\title{
AJK2015-02061
}

\section{INVESTIGATION OF UNSTEADY TIP CLEARANCE FLOW IN A LOW-SPEED ONE AND HALF STAGE AXIAL COMPRESSOR WITH LES AND PIV}

Chunill Hah ${ }^{1,}$ Michael Hathaway ${ }^{1,}$ Joseph katz ${ }^{2}$, and David Tan ${ }^{2}$

${ }^{1}$ NASA Glenn Research Center,

MS 5-10, Cleveland, Ohio

${ }^{2}$ Johns Hopkins University, Baltimore, Maryland 


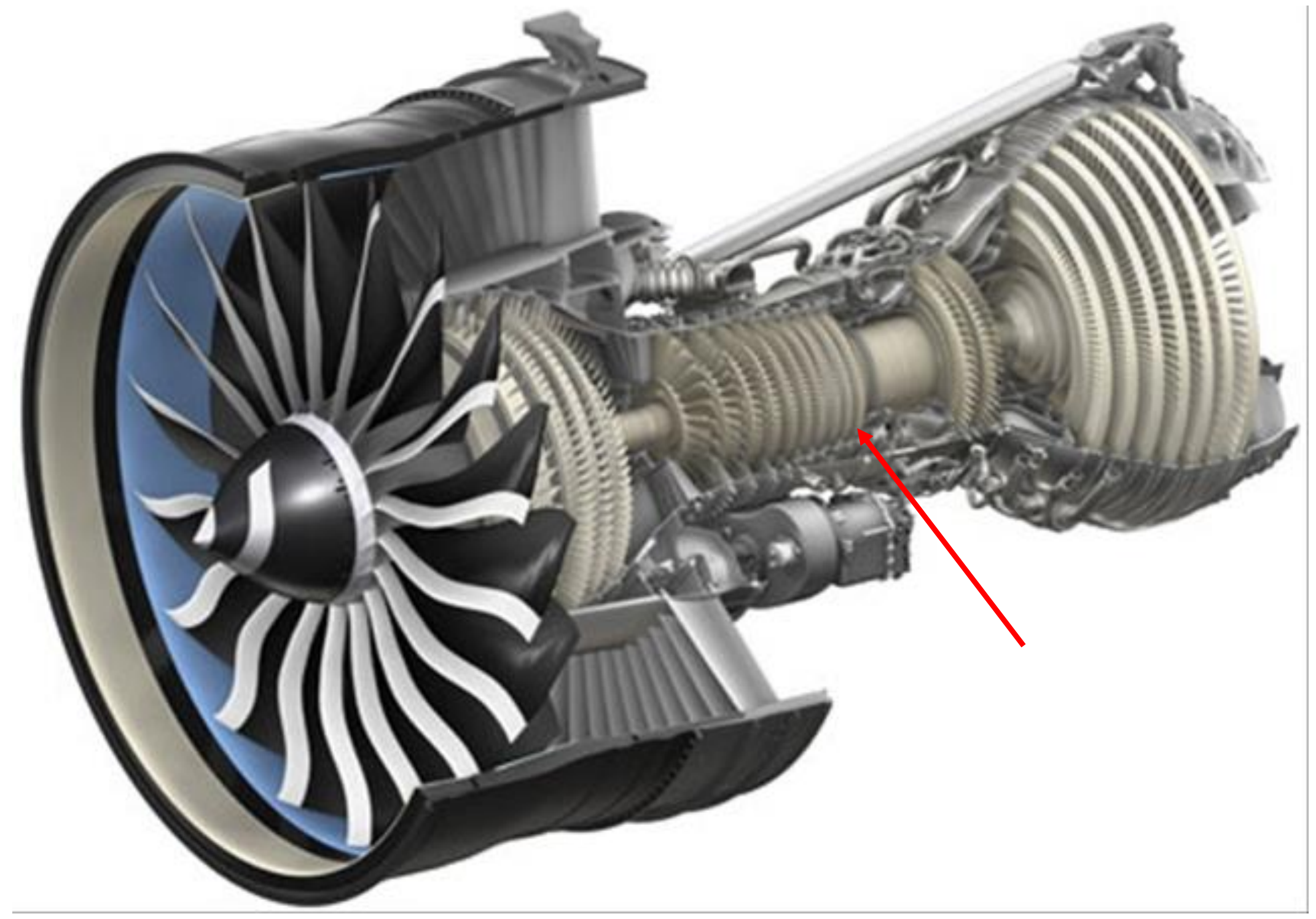




\section{Background}

- Large tip gap ( $3-5 \%$ of span) issue in rear stages of future small core engine.

- Efficiency, flow range, possible blade vibration.

- NASA NRA to study the flow and to develop strategies. 


\section{NASA's AATT NRA for compressor tip clearance flow (Johns Hopkins Univ.)}

- Detailed unsteady PIV measurement of tip gap flow in the JHU's index matched facility (one and half stage).

- To understand effects of large tip gaps in small axial compressor rear stages.

- Numerical study with LES : NASA in-house effort. 


\section{Tip clearance flow in tubomachinery}

- Traditionally handled as a steady flow; flow from pressure side of the blade to suction side of the blade across tip gap.

- Tip clearance flow is unsteady due to vortex shedding, tip vortex oscillation, blade interaction, etc. (sheet tip vortex is known as unstable).

- Unsteady characteristics are vital for flow instability, flow control, cavitation prediction. 


\section{Objectives}

1. Study of unsteady nature of tip clearance flow ( tip vortex oscillation, instability vortex, vortex break down, nonsynchronous blade vibration) with LES.

- conducted in one and half stage low speed axial compressor with two tip gaps $(0.5 \& 2.3 \%$ tip chord)

- $0.5 \& 2.3 \%$ tip chord correspond $1.1 \& 5.1 \%$ span.

2. Comparison between PIV data and LES results. 


\section{Order of presentation}

- One and half stage axial compressor test article scaled from the NASA research low speed axial compressor.

- Test rig and PIV setup at Johns Hopkins University.

- Detailed tip clearance flow investigation with PIV and LES.

- Observations and concluding remarks. 


\section{JHU test compressor cross section}

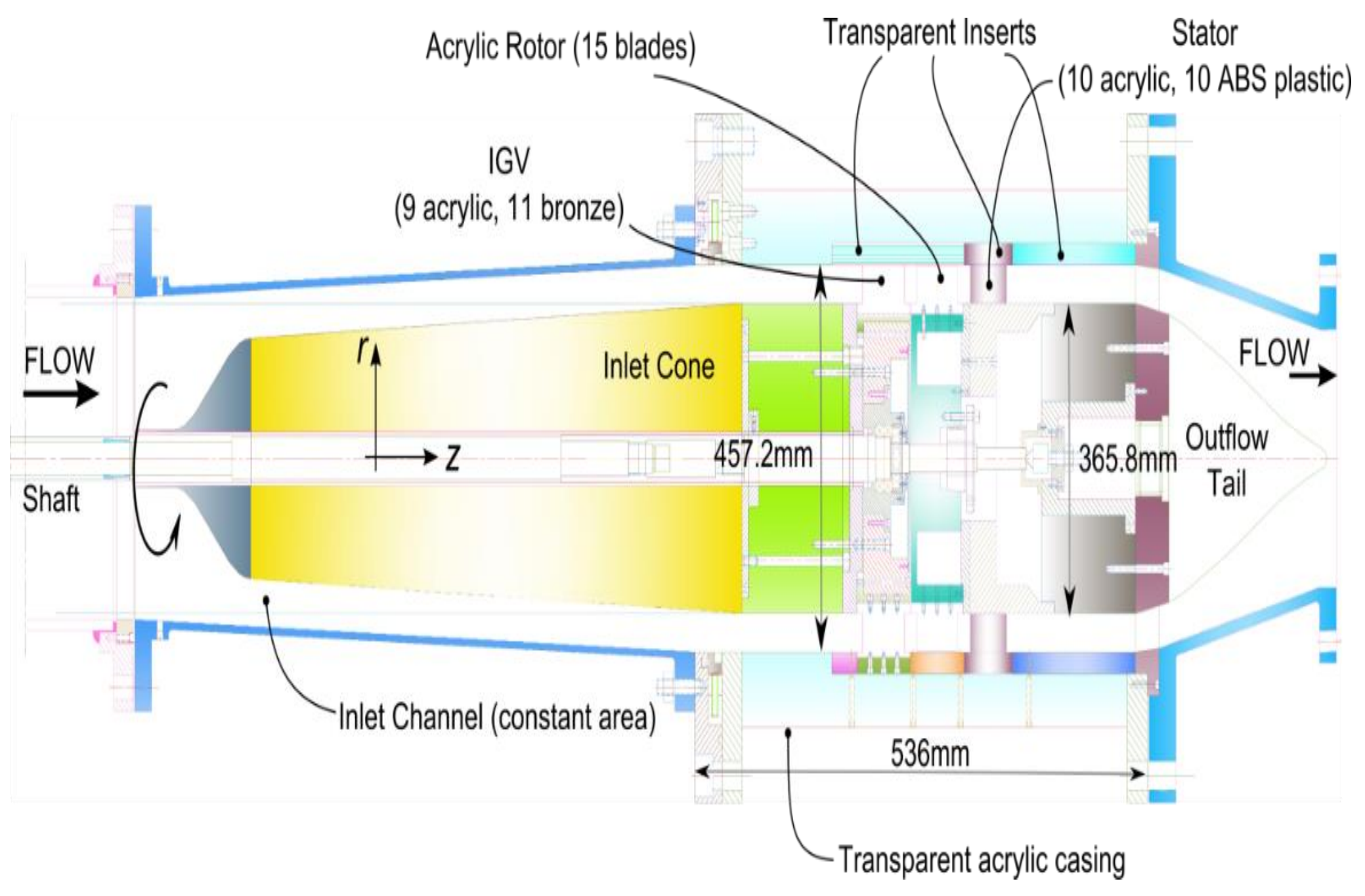




\section{New Facility - Images}

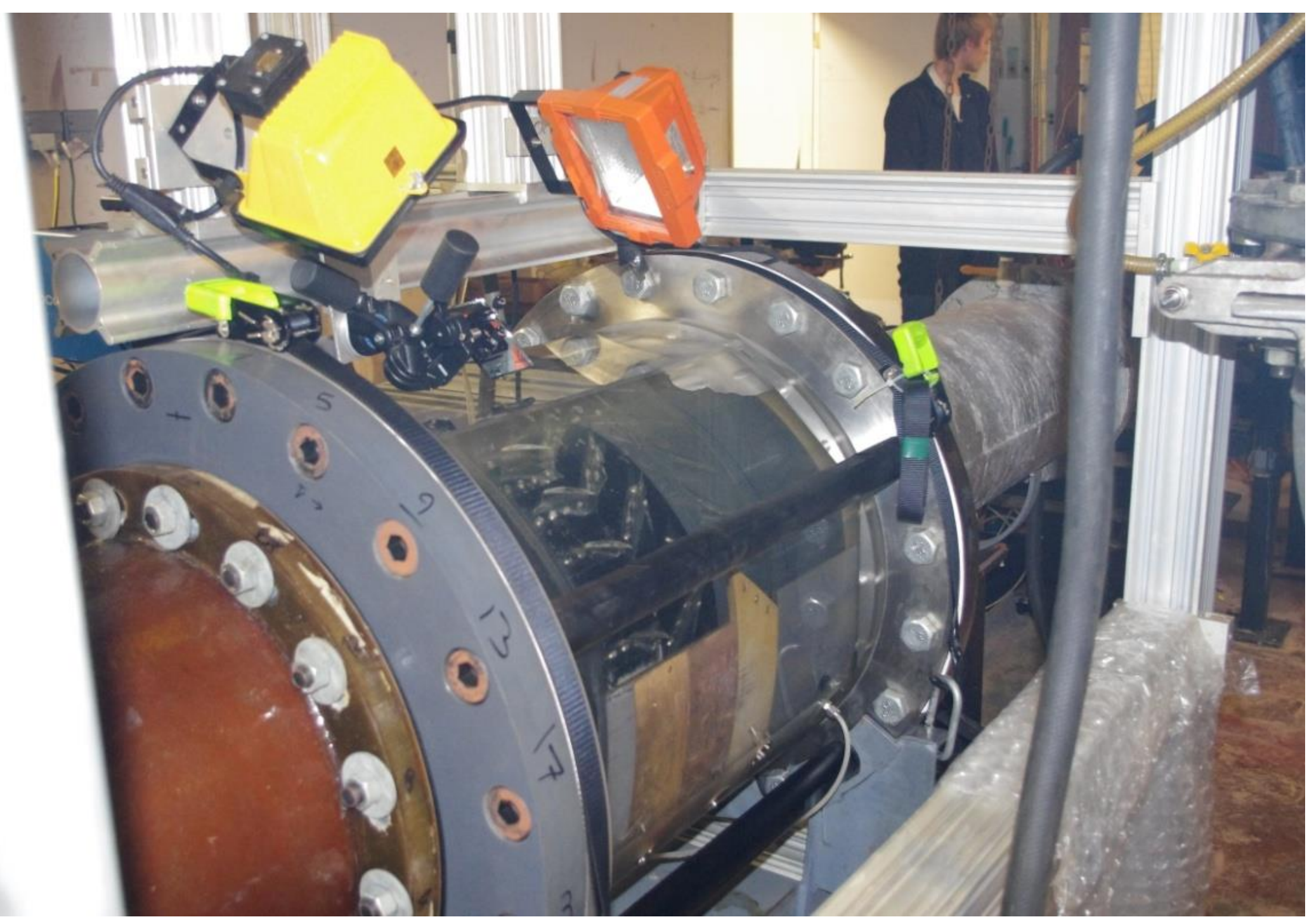




\section{One and half stage axial compressor}

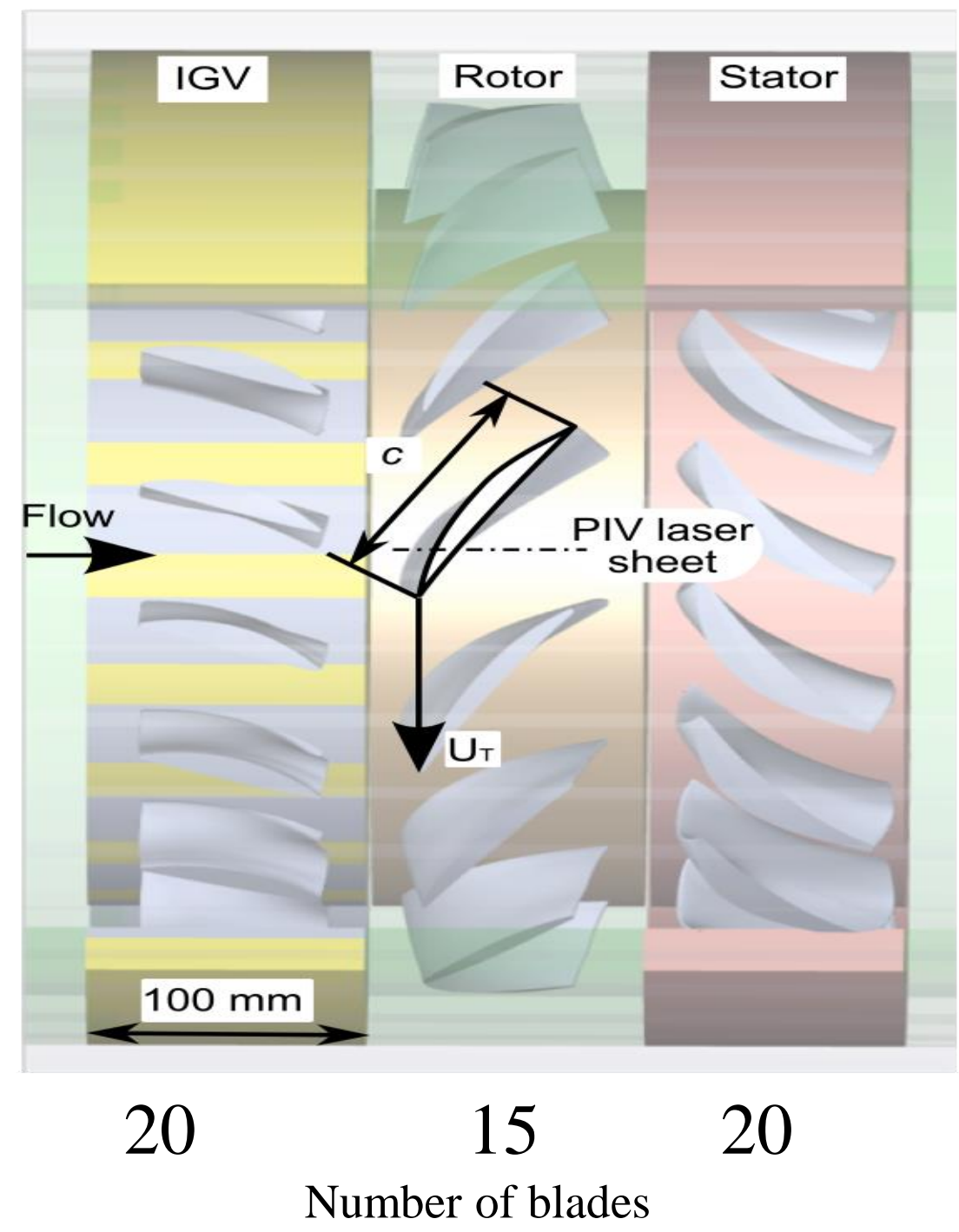




\section{Pressure rise characteristics}

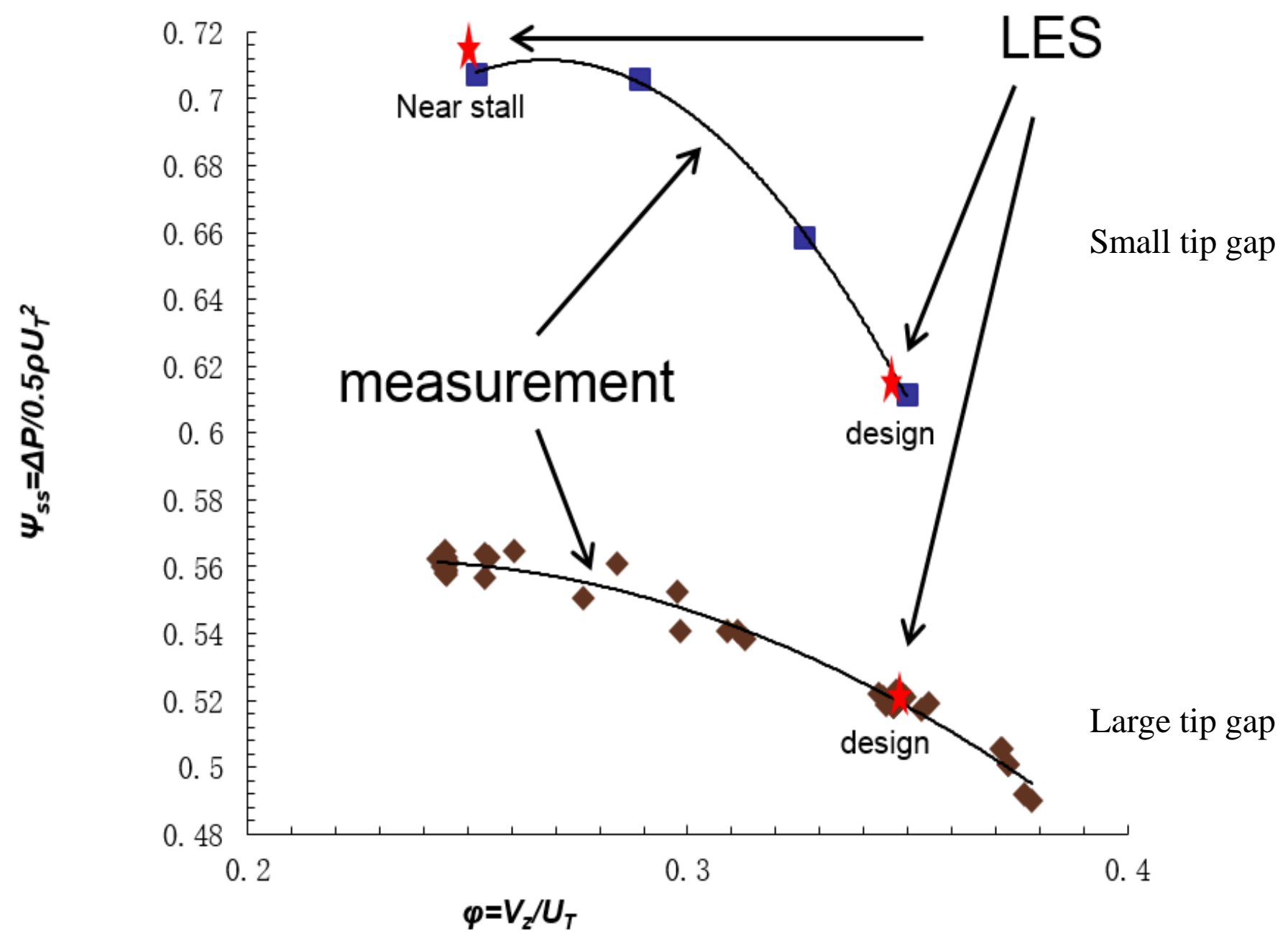




\section{LES for unsteady tip clearance flow in compressors}

- URANS : Effects due to entire turbulence scales are modeled. Solution depends on turbulence model. Difficult for separated flow, flow transition, Reynolds number effects.

- LES : Significant increase in computing cost. Requires large computational grid. Needs further development/validation for high speed flow. 


\section{Applied LES procedure}

- $3^{\text {rd }}$-order scheme for convection terms.

- $2^{\text {nd }}$-order central differencing for diffusion terms.

- Sub-iteration at each time step.

- Dynamic model for sub grid stress tensor.

- Multi-block I-grid, 980 million nodes for all blade passages with 74 radial nodes inside tip gap.

- Incompressible flow simulation. 


\section{Computational grid and domain}

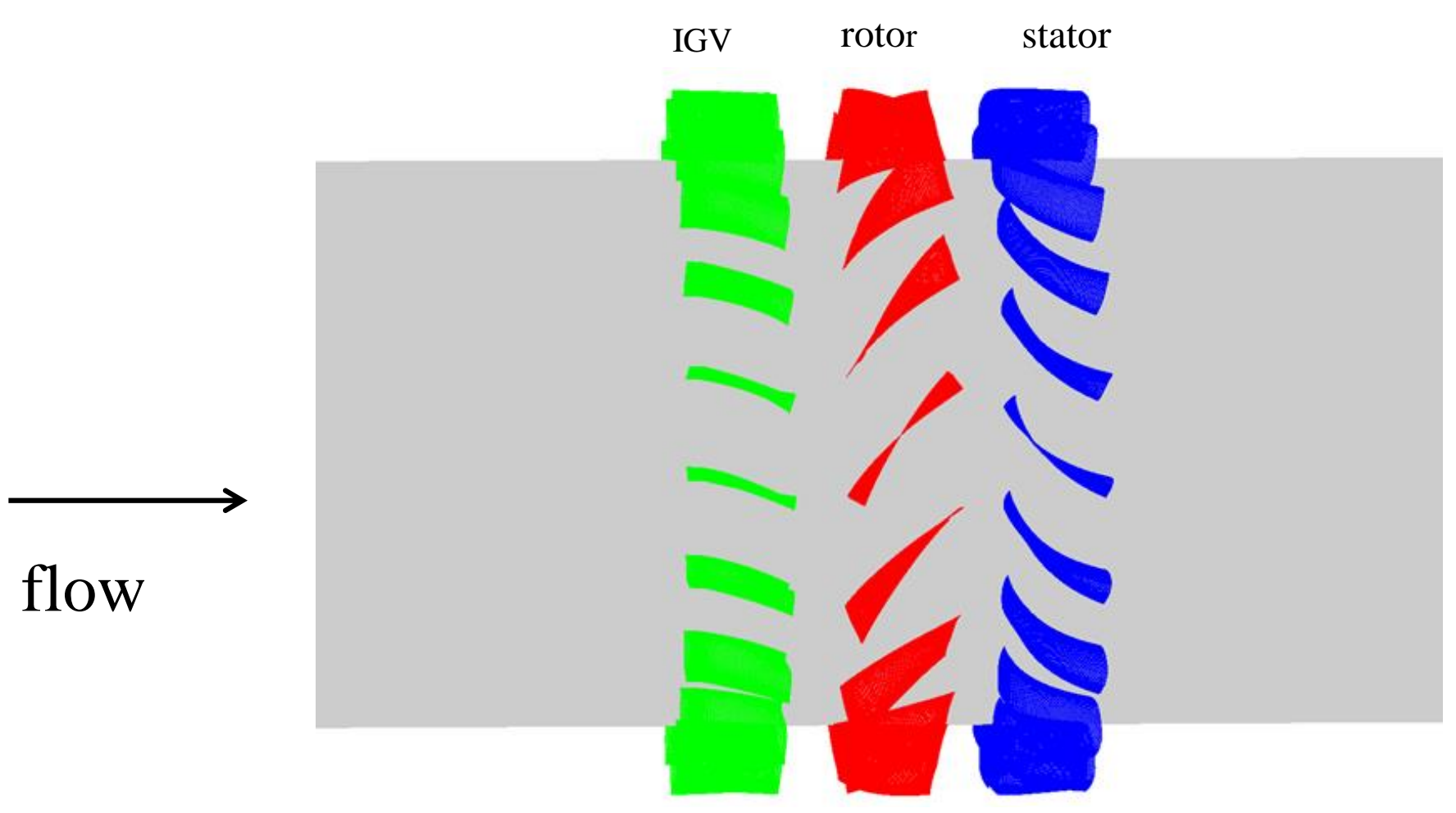




\section{Instantaneous vorticity contours at $20 \%$ span}

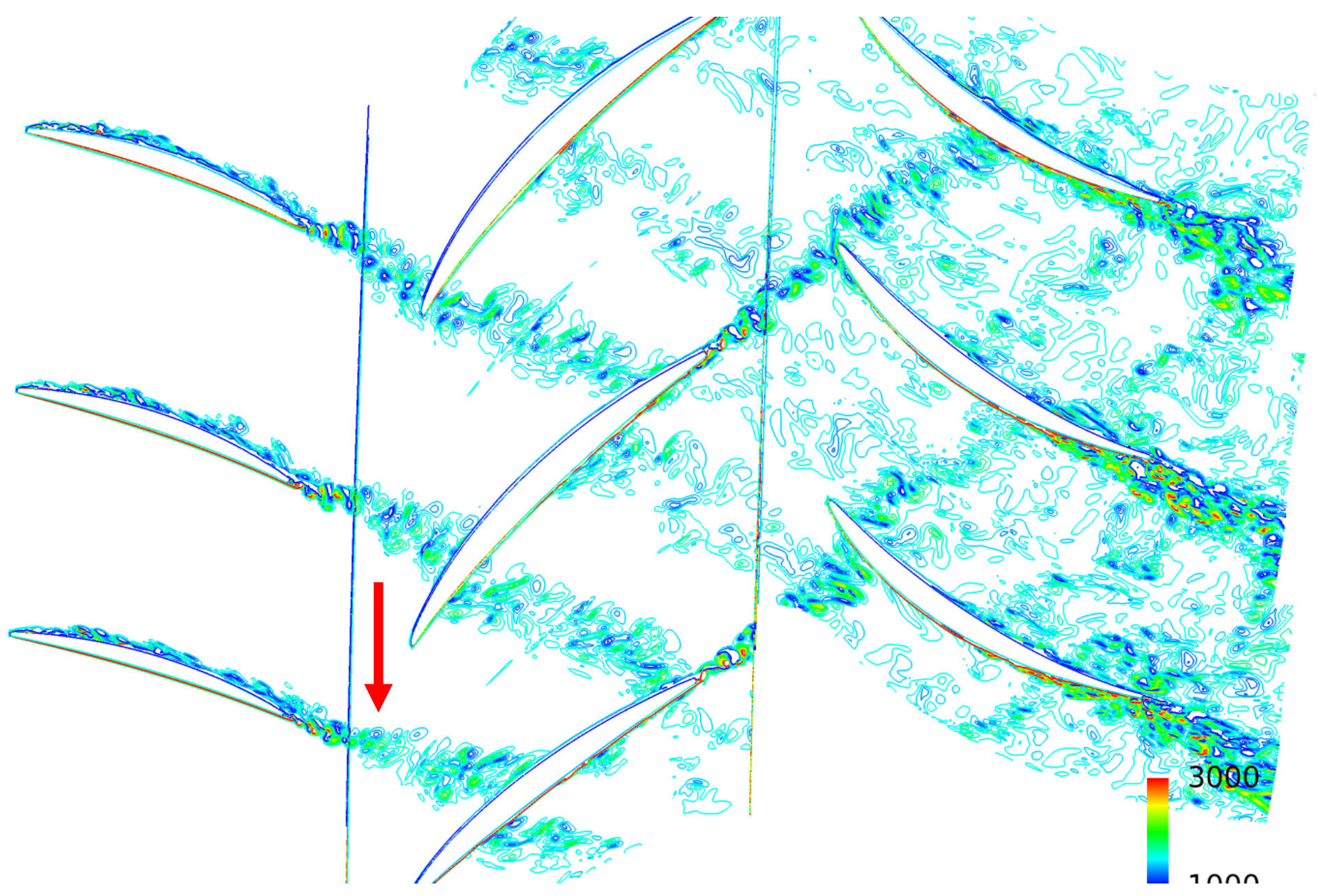




\section{Instantaneous vorticity contours at rotor tip}

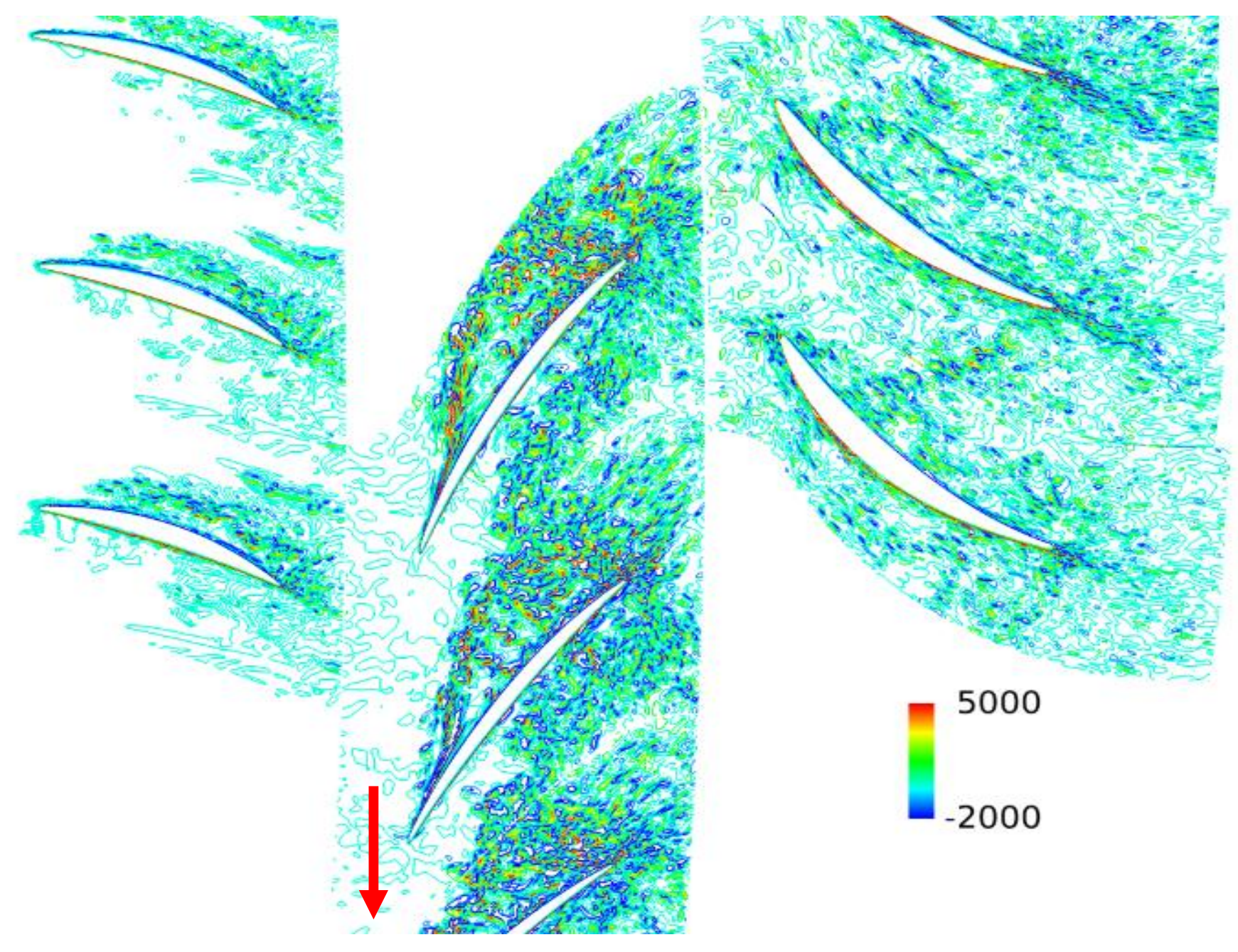




\section{Tip clearance vortex structure at three flow conditions}

- Comparison between flow visualization with cavitation and LES.

- $0.5 \mathrm{~mm}$ tip gap : peak efficiency and near stall.

- $2.4 \mathrm{~mm}$ tip gap : peak efficiency.

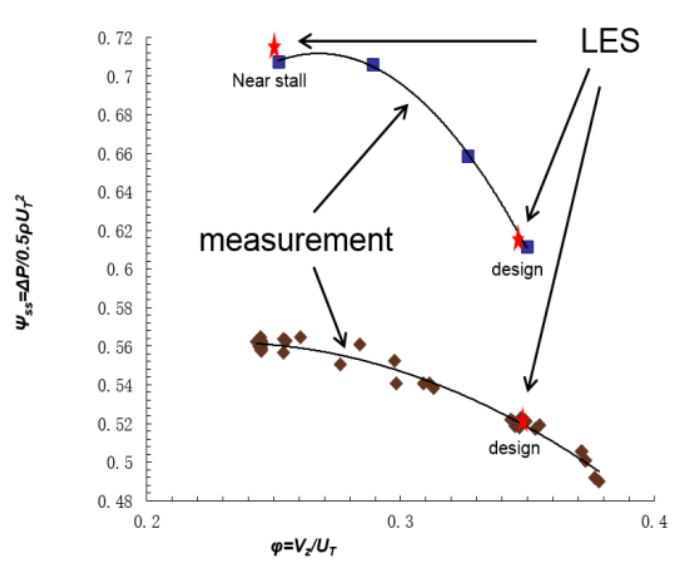




\section{Comparison of tip gap flow structure, $0.5 \mathrm{~mm}$ gap, design condition}

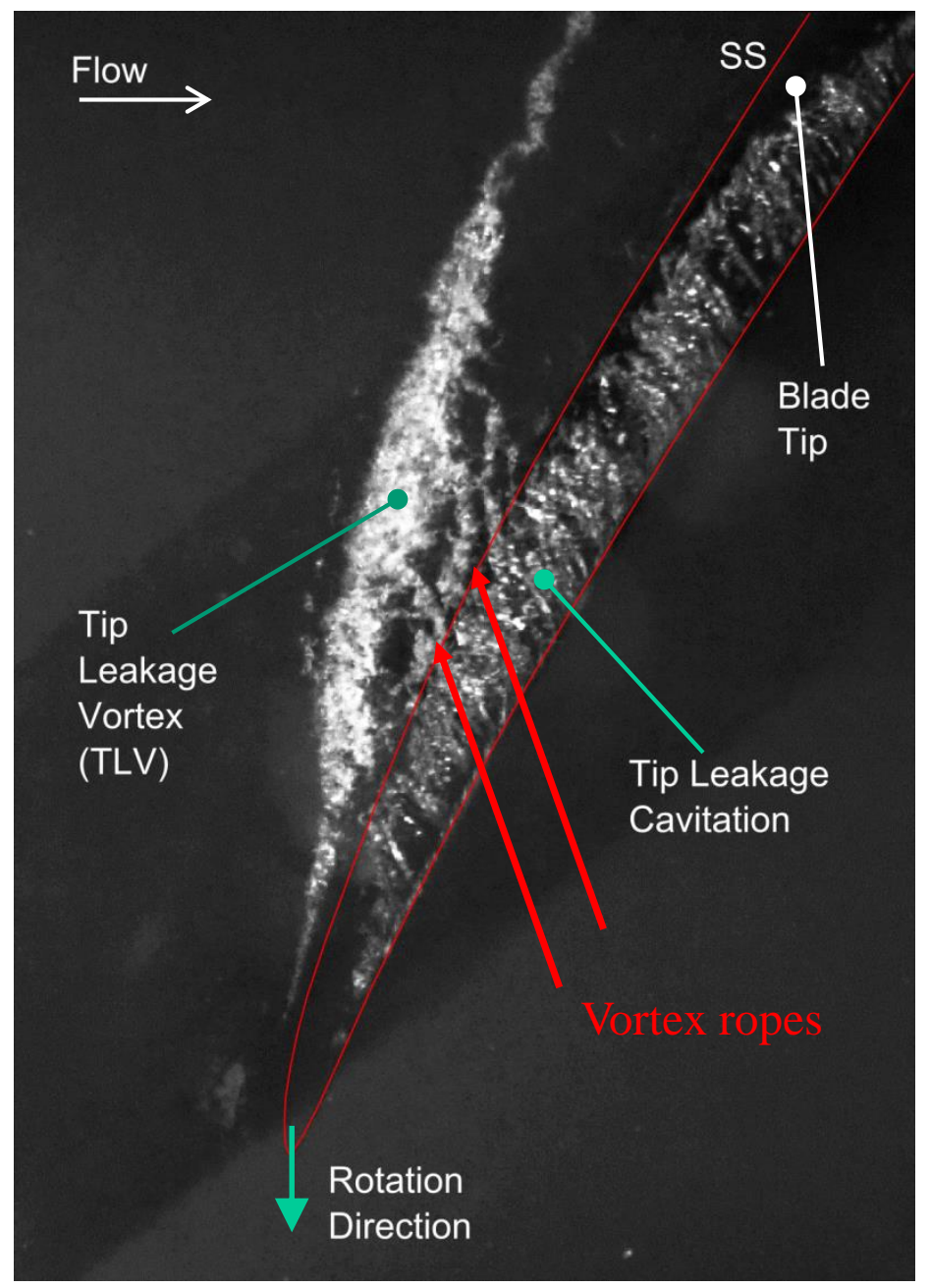




\section{Comparison of tip gap flow structure, $0.5 \mathrm{~mm}$ gap, near stall condition}
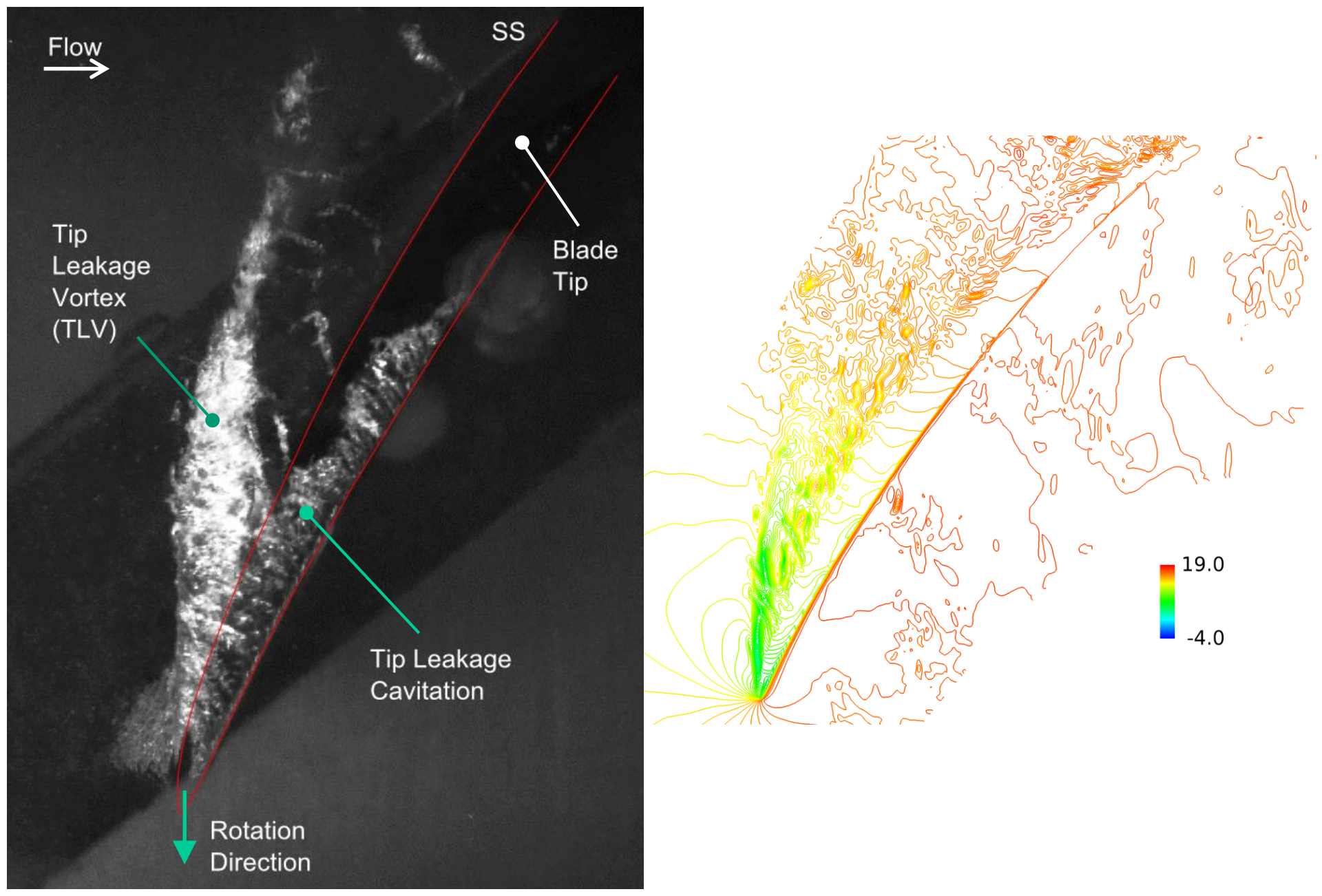

Cavitation visualization

Static pressure from LES 


\section{Comparison of tip gap flow structure, $2.4 \mathrm{~mm}$ gap, design condition}

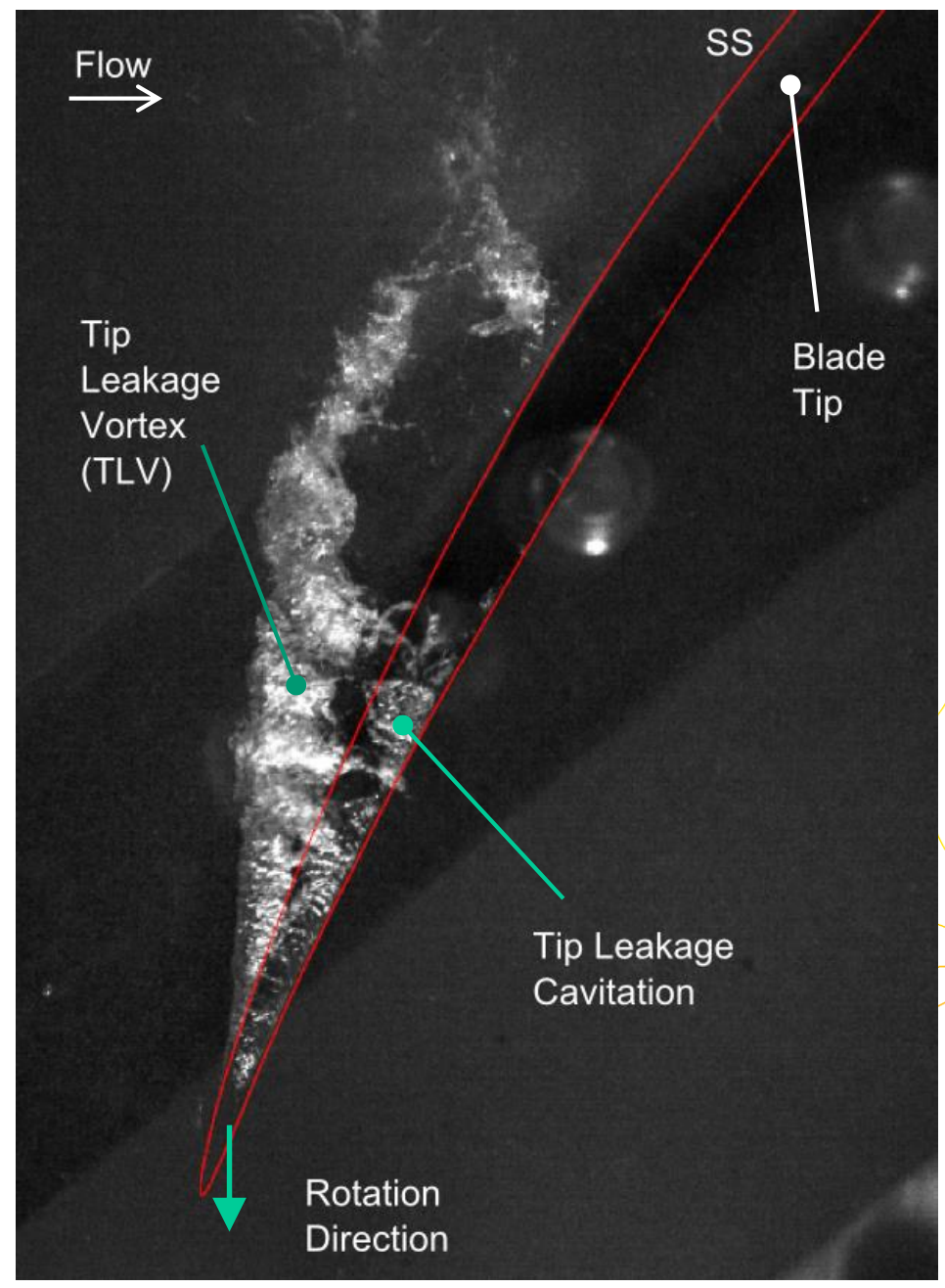

Cavitation visualization

Static pressure from LES 


\section{Instantaneous velocity vectors, $0.5 \mathrm{~mm}$ gap, design condition, $0.02 \mathrm{~mm}$ above tip}

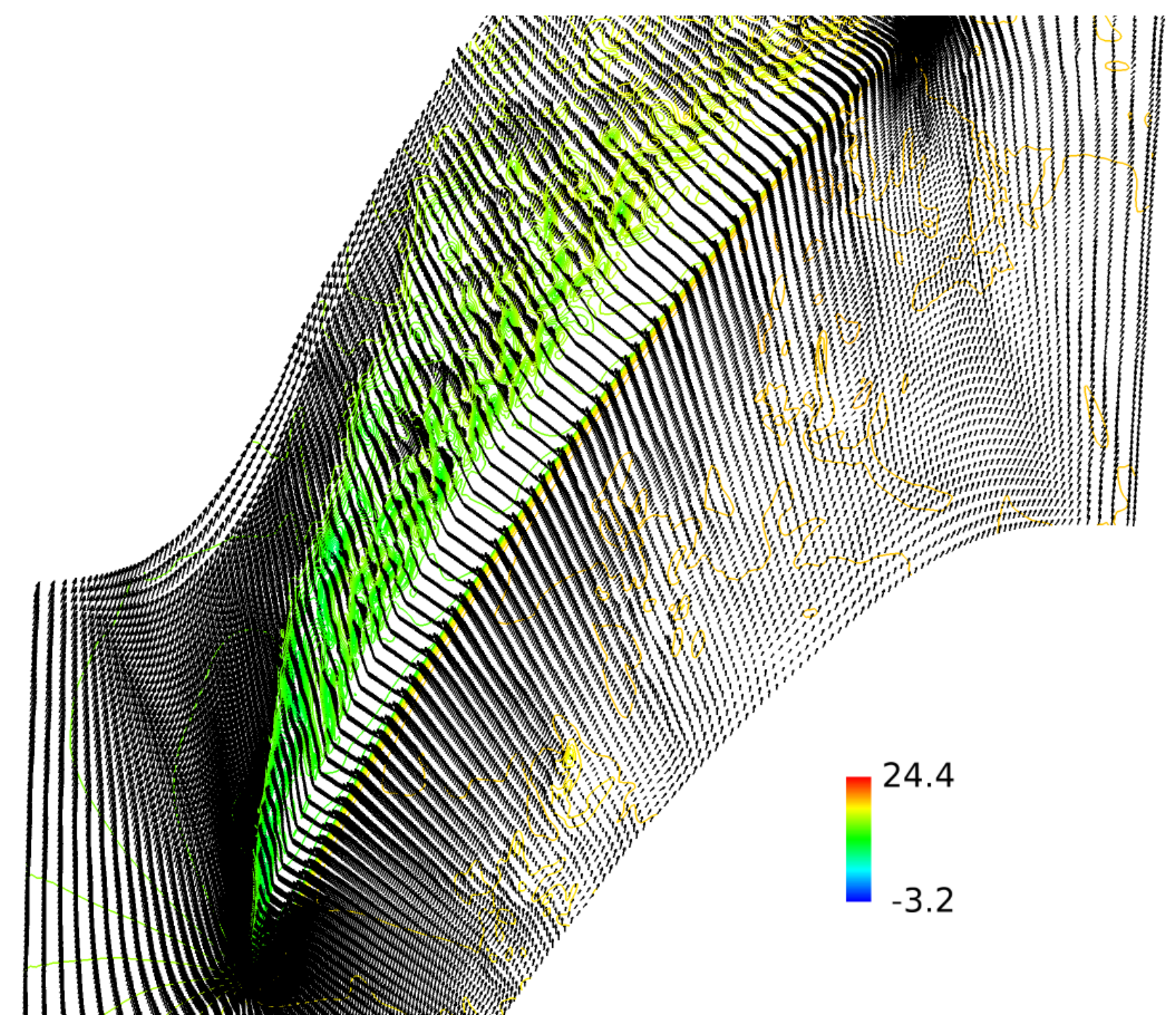




\section{Instantaneous velocity vectors, $0.5 \mathrm{~mm}$ gap, near stall condition, $0.02 \mathrm{~mm}$ above tip}

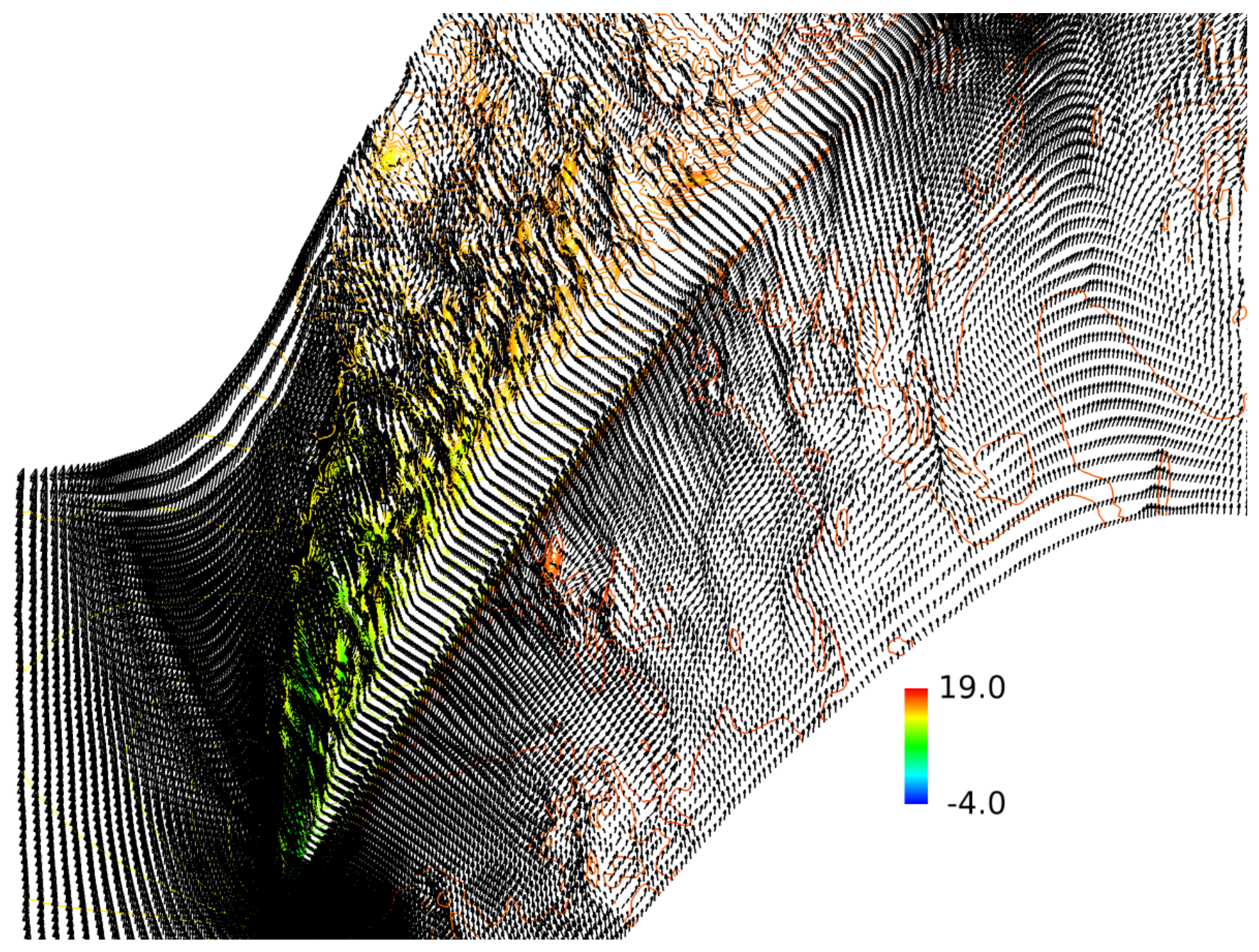




\section{Change in pressure field, $0.5 \mathrm{~mm}$ gap, near stall}

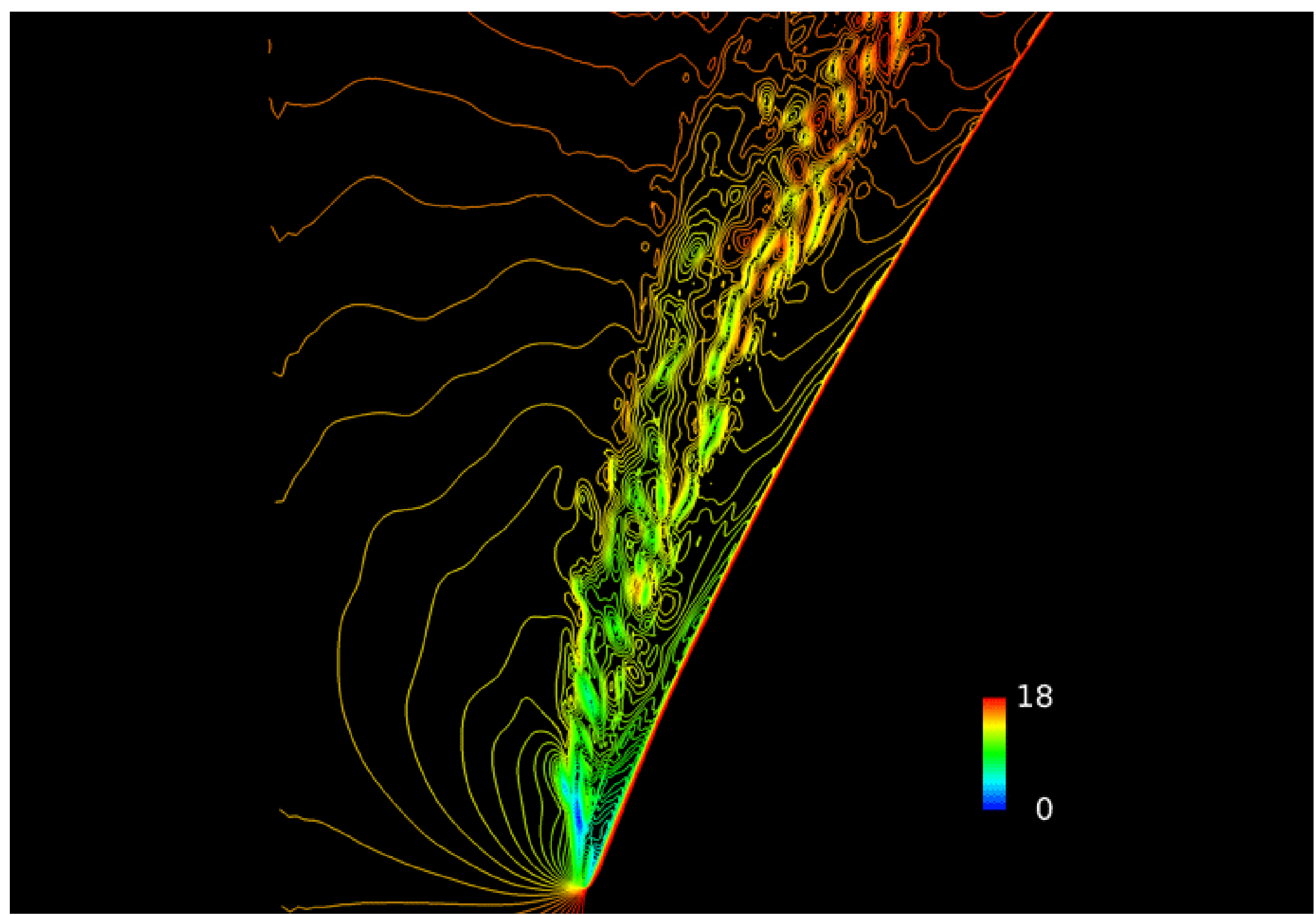




\section{Change in velocity field, $0.5 \mathrm{~mm}$ gap, near stall}

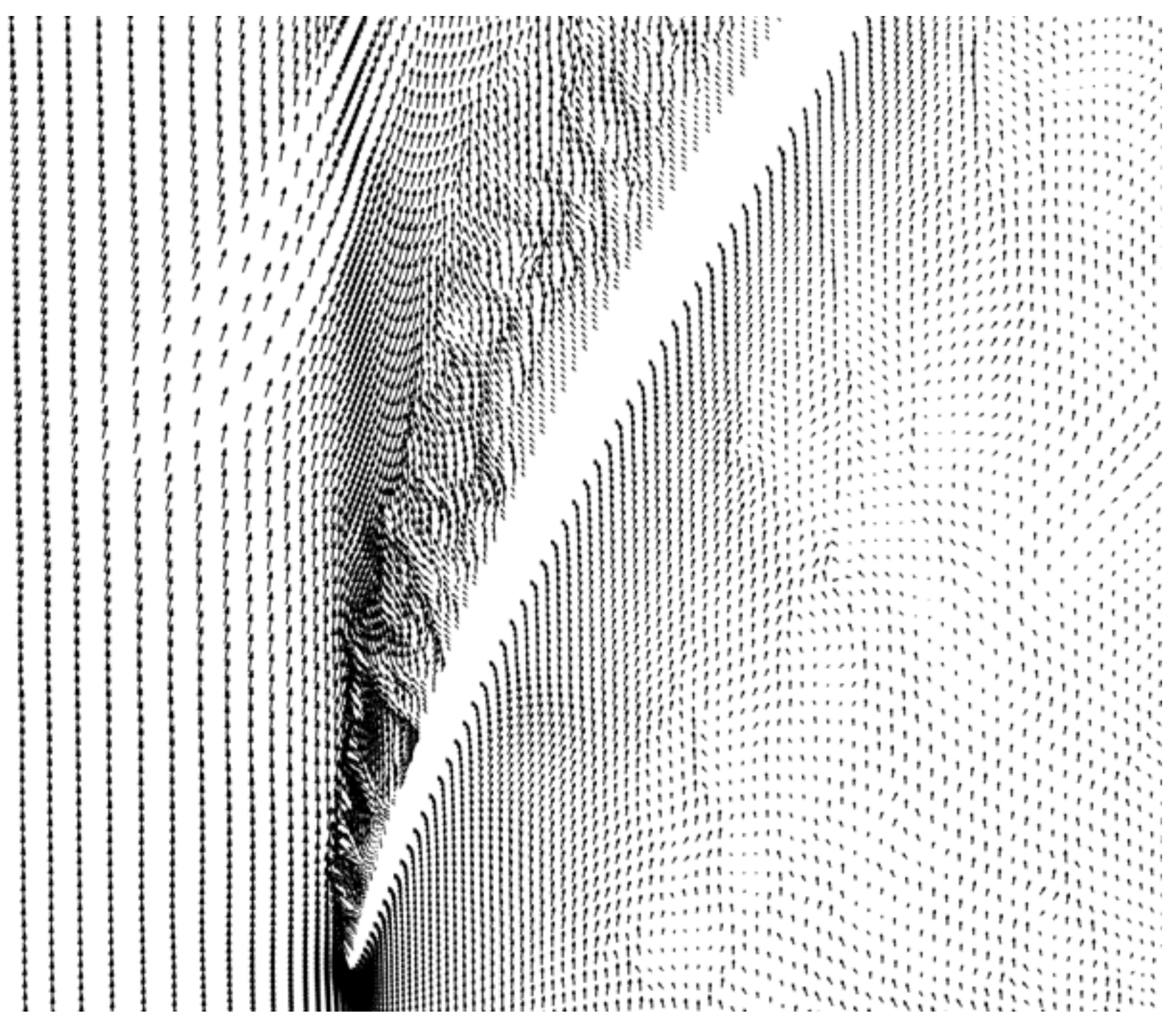




\section{Instantaneous velocity vectors, $2.4 \mathrm{~mm}$ gap, near stall condition, $0.02 \mathrm{~mm}$ above tip}

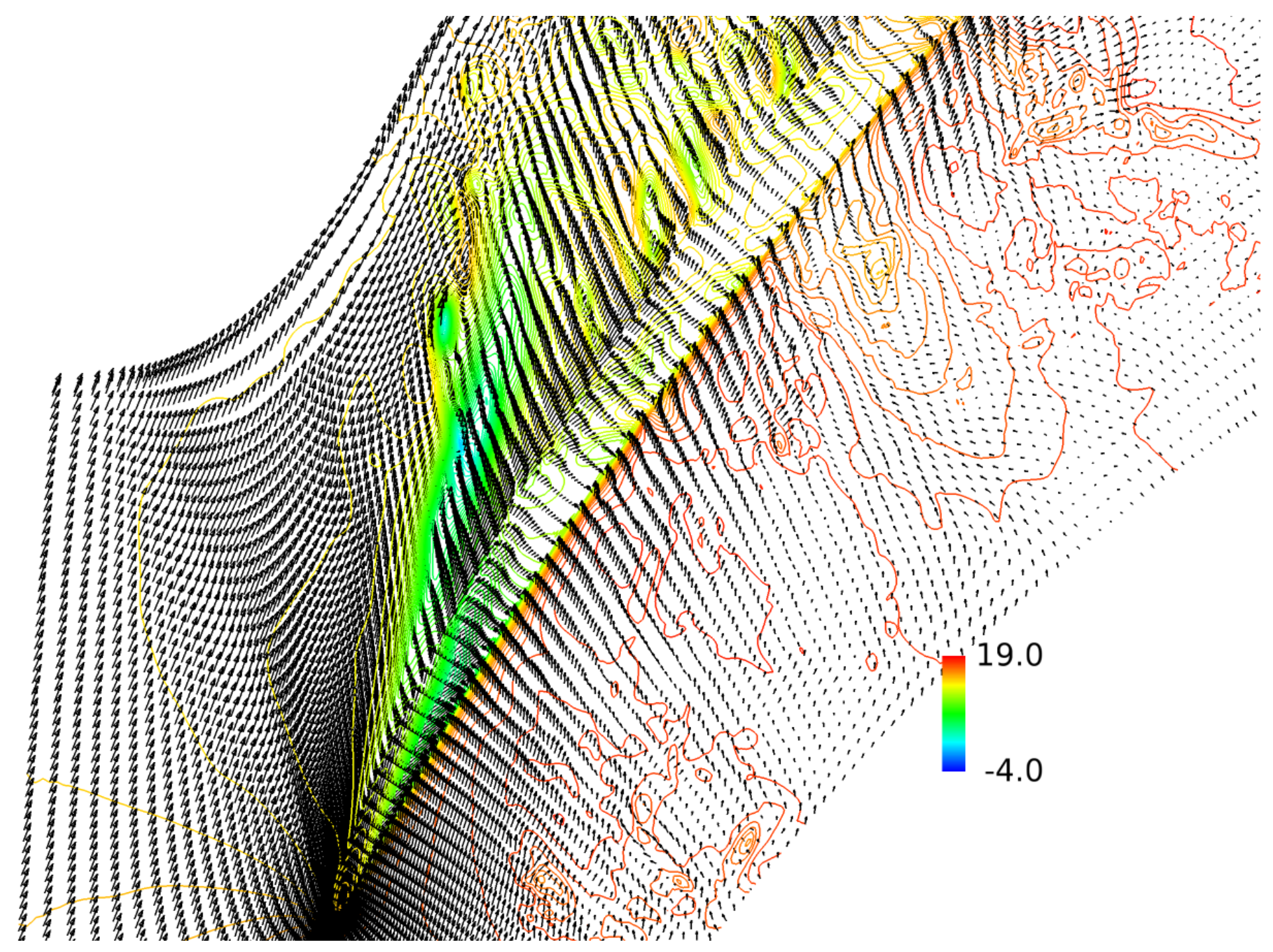




\section{Tip vortex structure from visualization and LES}

- Tip vortex structures from LES agree well with the visualization.

- Tip flow is unsteady at all flow conditions.

- The role of vortex ropes? 


\section{Meridional planes of PIV measurements}

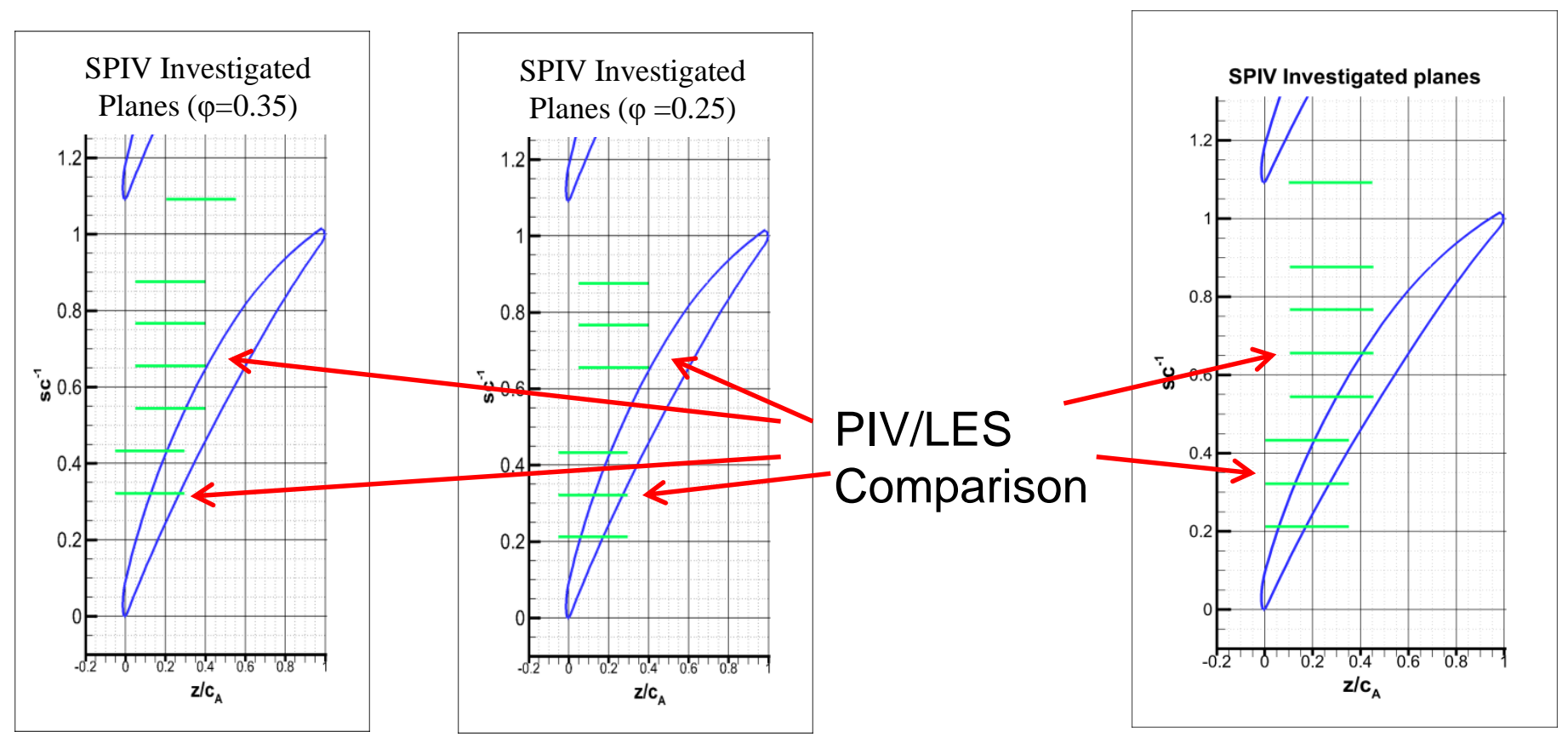

$0.5 \mathrm{~mm}$ tip gap

$2.3 \mathrm{~mm}$ tip gap 


\section{Instantaneous vorticity distribution around tip vortex from LES}

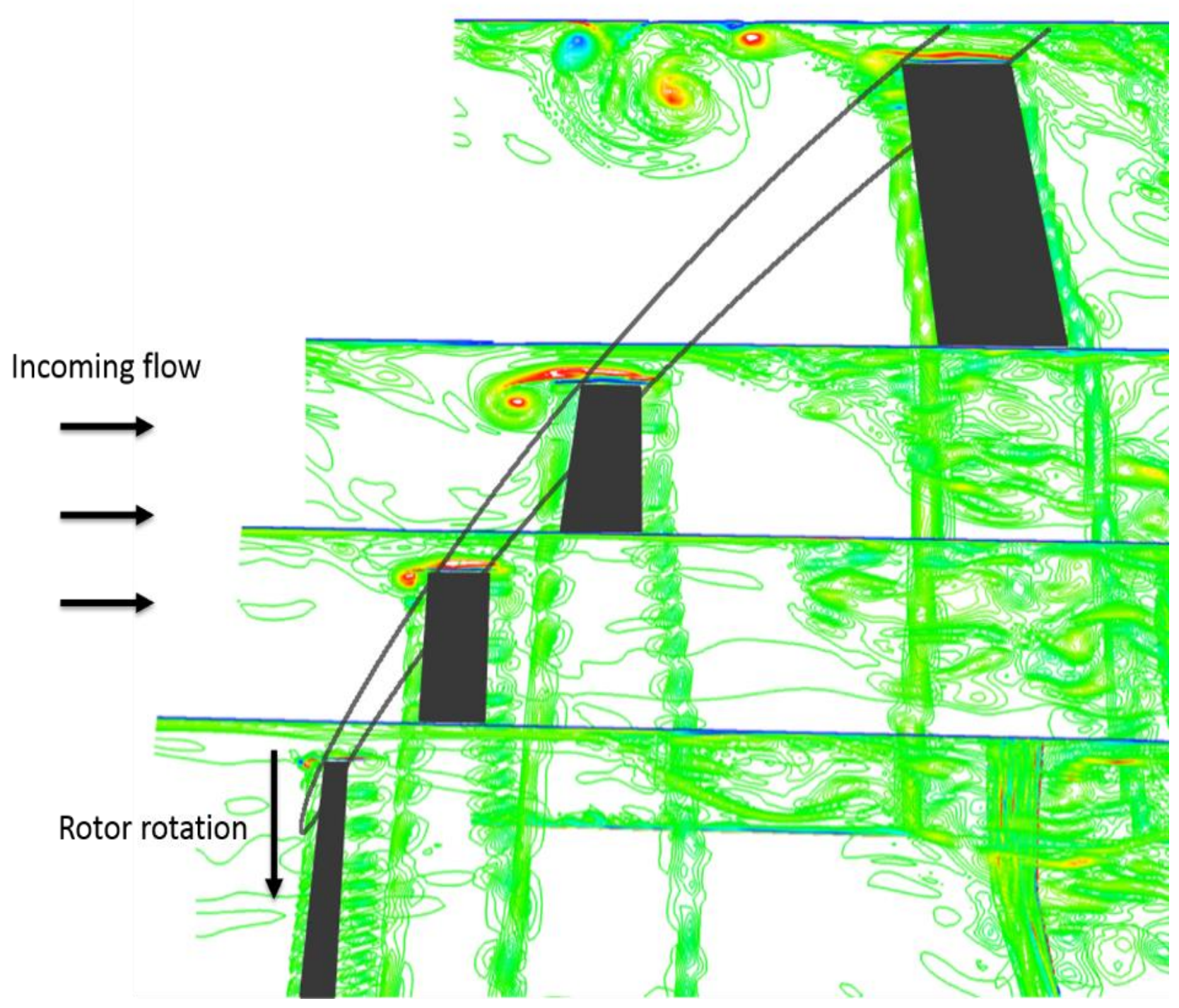




\section{Mechanism of tip clearance vortex generation from LES}

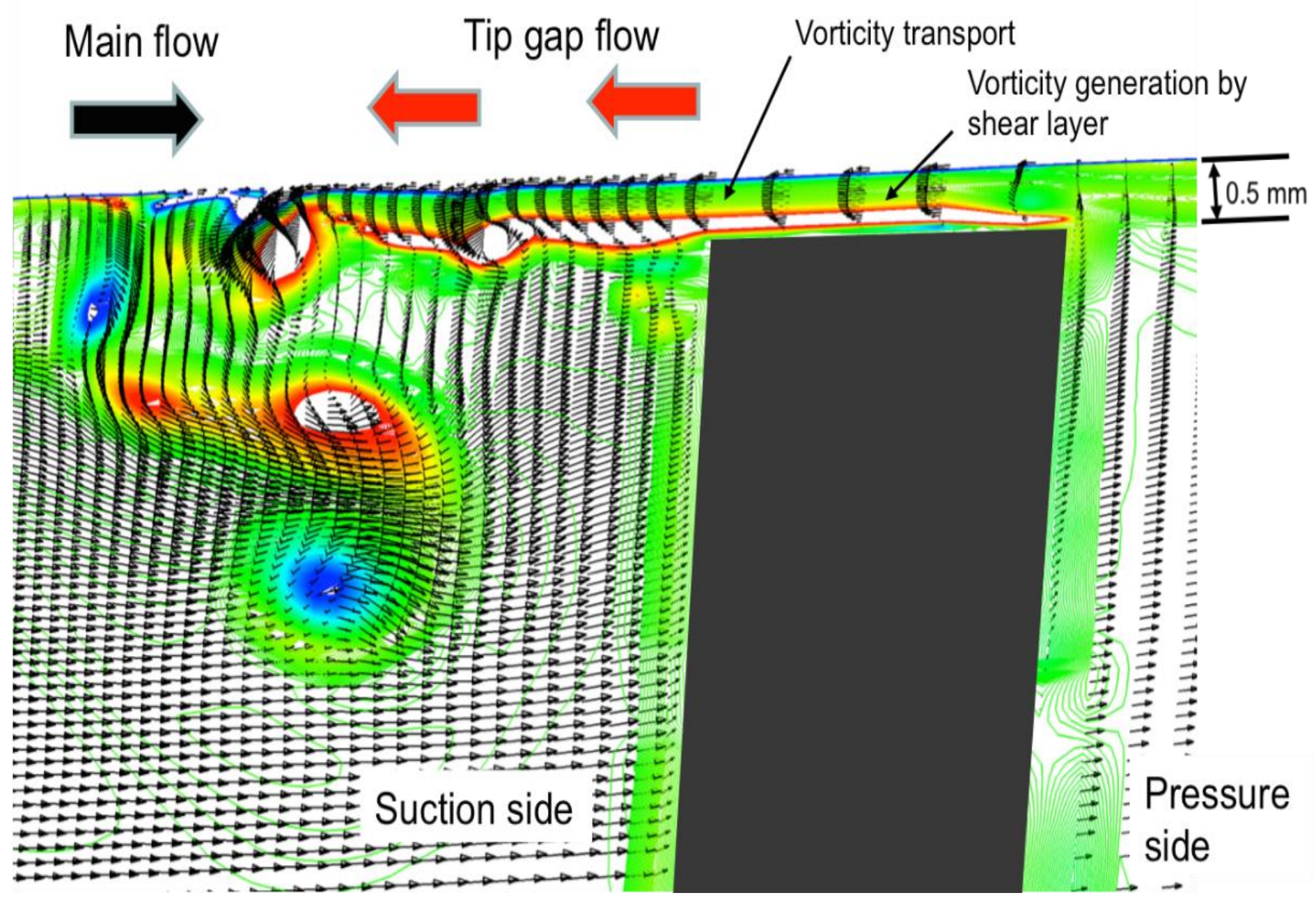




\section{Mechanism of tip clearance vortex}

\section{generation}

- Tip clearance vortex is generated by the shear layers on the blade tip and casing wall, not from the collision of main tip flow and the incoming main passage flow.

- This understanding will help in developing future strategy to control the tip clearance flow at near stall operation. 


\section{Comparisons of tip vortex at design condition and near stall, $0.5 \mathrm{~mm}$ gap, $\mathrm{s} / \mathrm{C}=\mathbf{0 . 3 2 8}$}

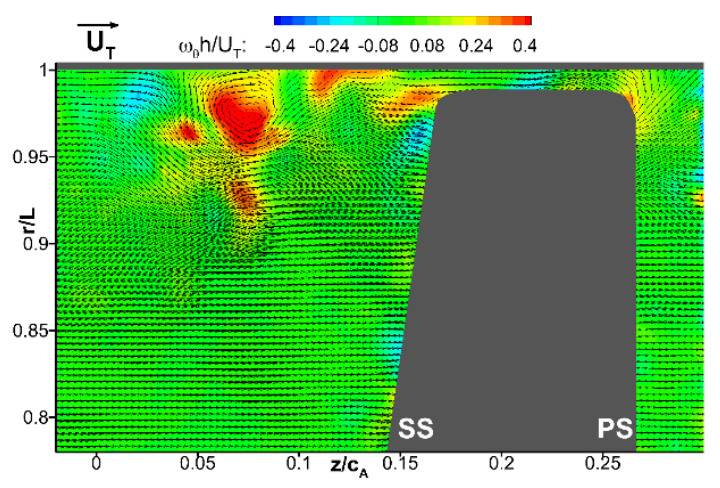

design

$$
1
$$

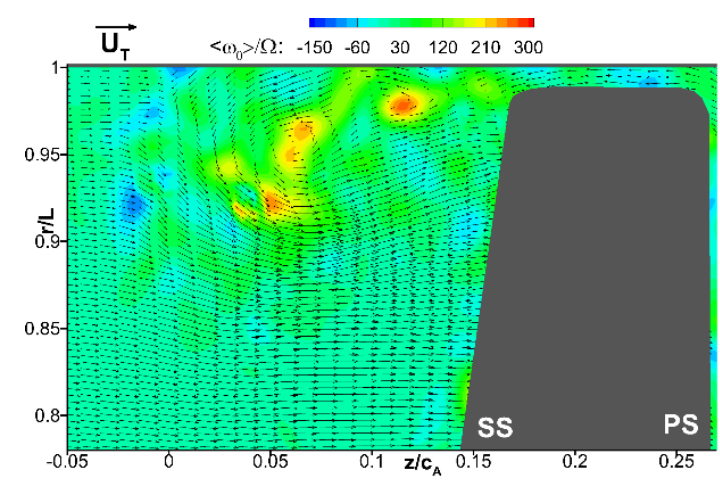

Near stall

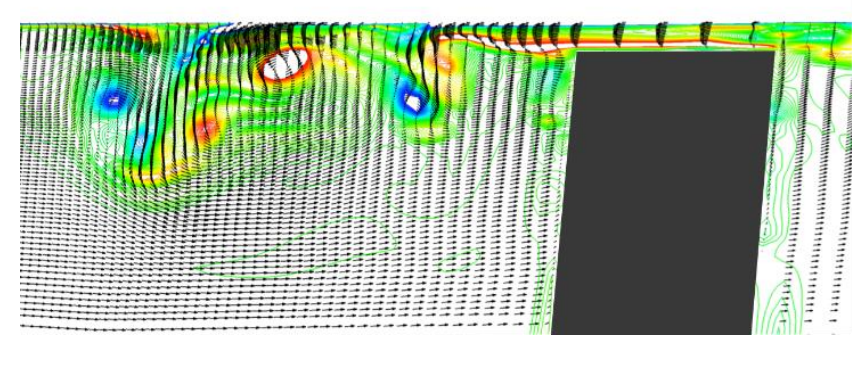

LES 


\section{Comparisons of tip vortex with two tip gaps $(0.5$ $\mathrm{mm}$ and $2,4 \mathrm{~mm}$ at design condition, $\mathrm{s} / \mathrm{C}=\mathbf{0 . 3 2 8}$}

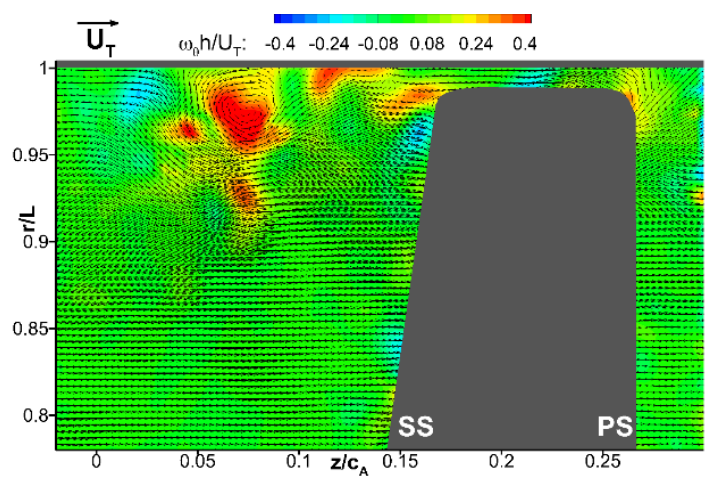

$0.5 \mathrm{~mm}$

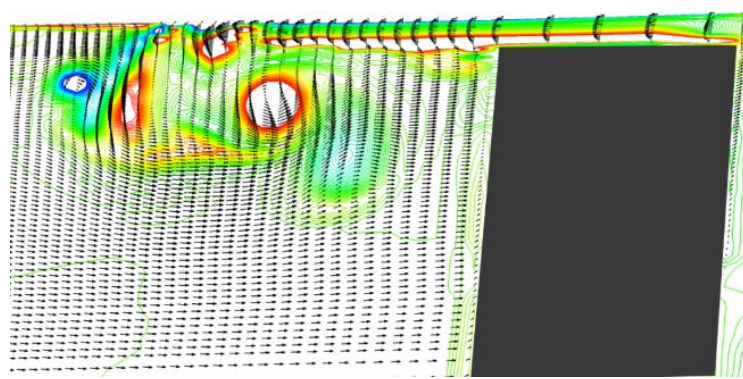

$\sqrt{7}$

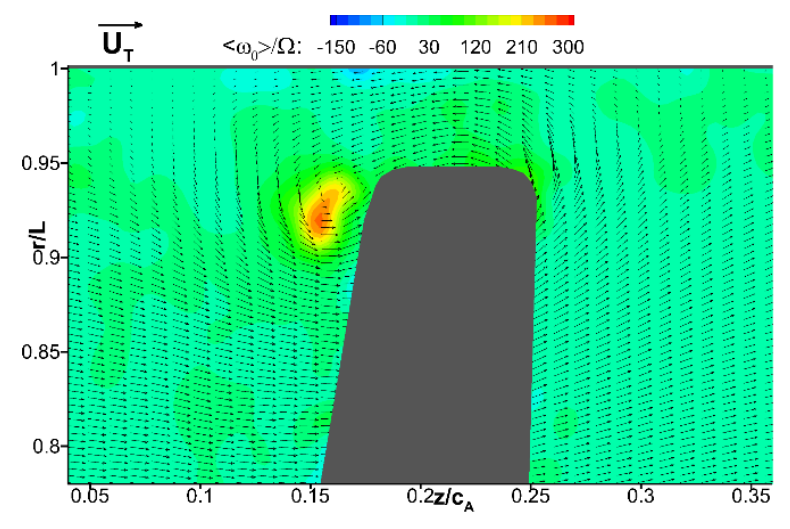

$2.4 \mathrm{~mm}$

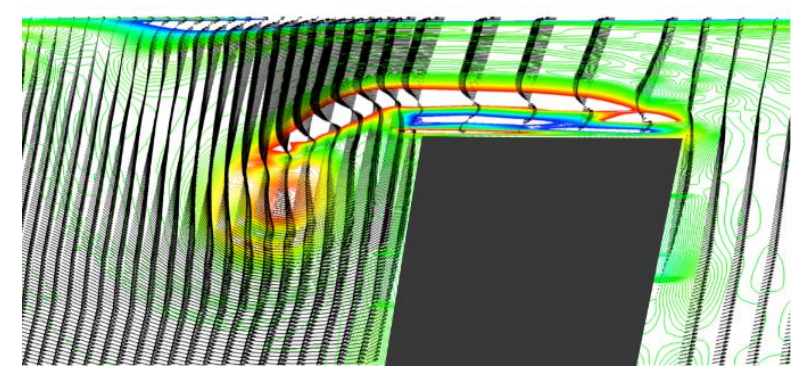

PIV

LES 


\section{Changes of velocity vectors near tip gap at $\mathrm{s} / \mathrm{c}=\mathbf{0 . 3 2 8}$}
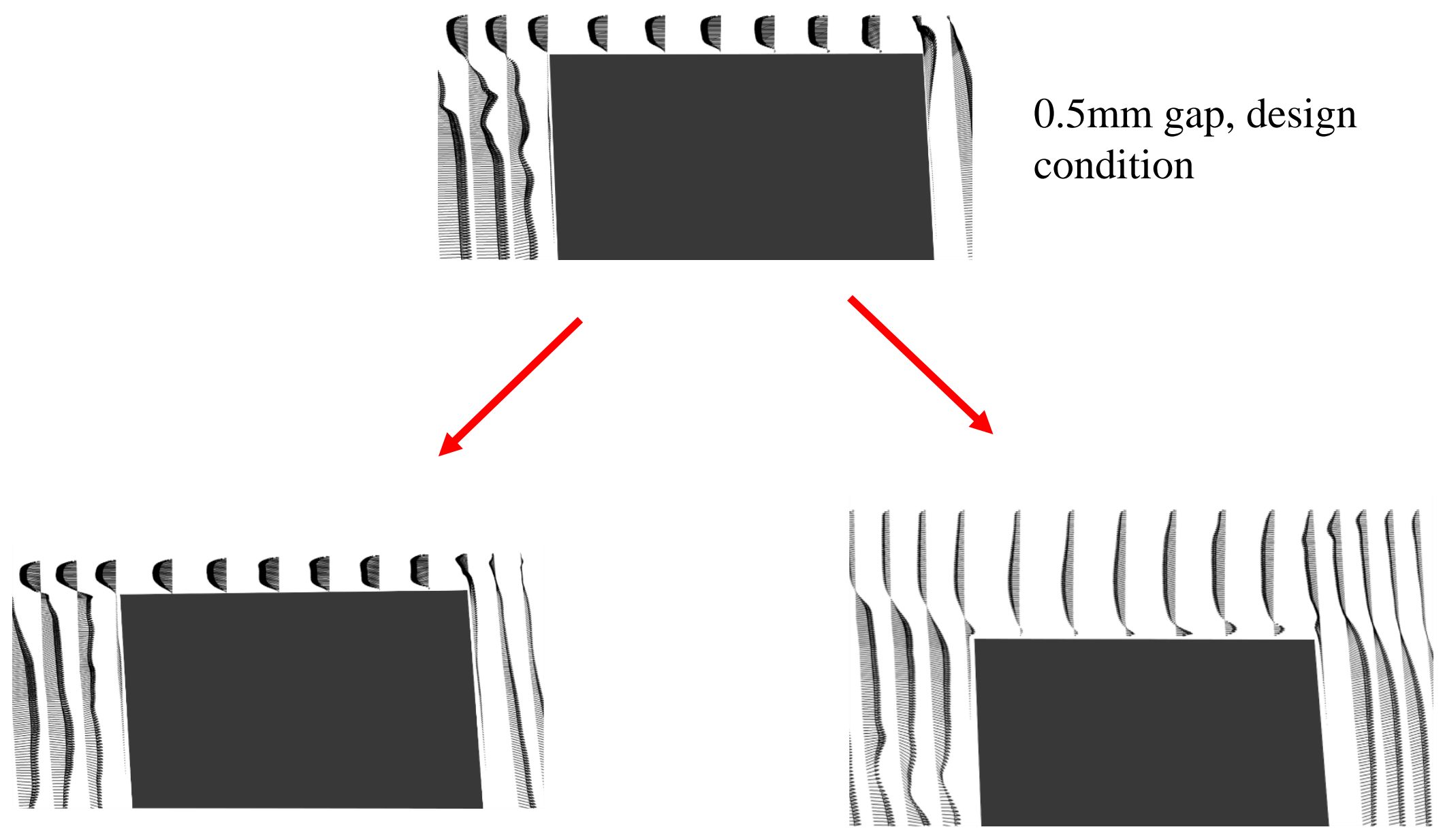

$0.5 \mathrm{~mm}$ gap, near stall

$2.4 \mathrm{~mm}$ gap, design condition 
Effects of tip gap size and flow rate on tip vortex structure

- Tip vortex starts early, move away from the blade further, and radially mover further inward when mass flow rate is decreased (0.5 mm tip gap).

- Tip vortex stays closer to blade tip when tip gaps is increased at design condition. 


\section{Changes in tip vortex structure, $2.4 \mathrm{~mm}$ and $\mathrm{s} / \mathrm{c}=\mathbf{0 . 6 5 5}$}

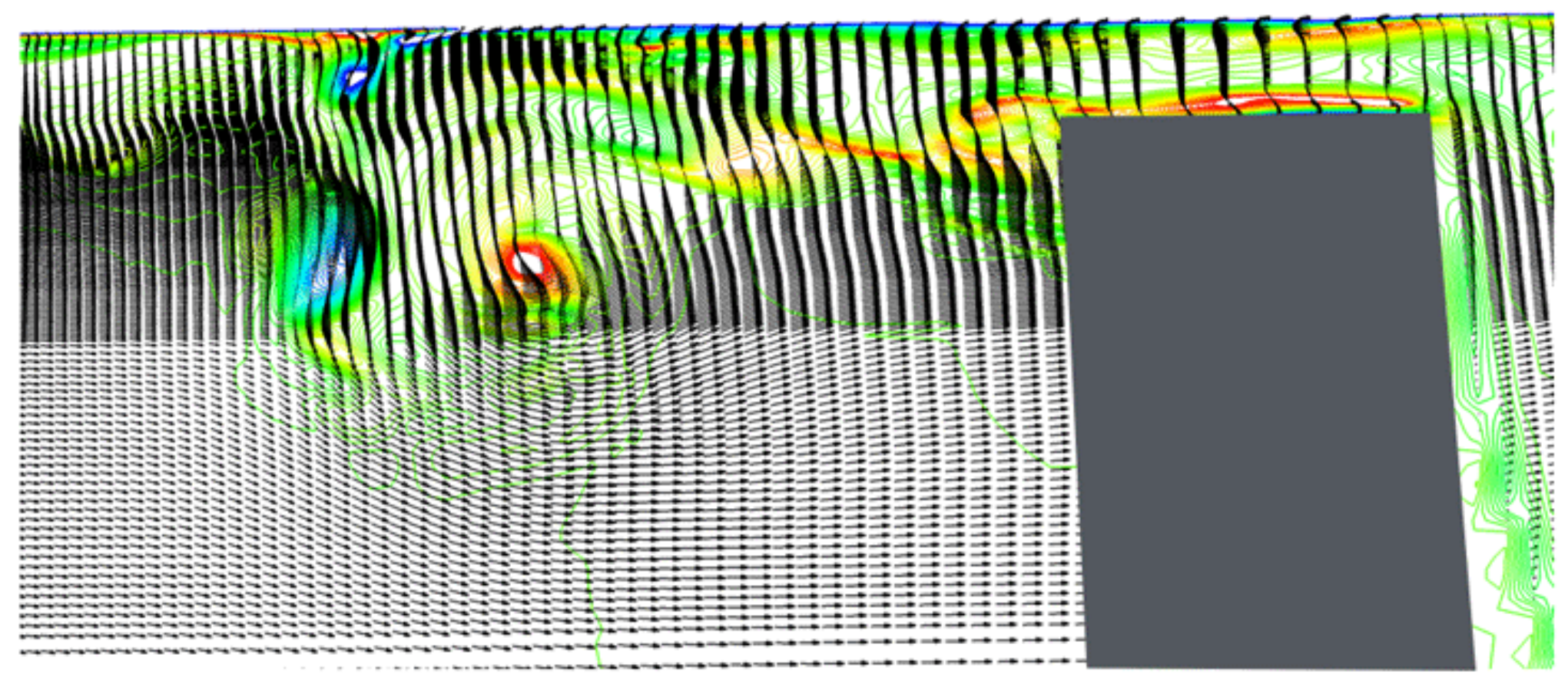




\section{Time-averaged tip vortex structure, $2.4 \mathrm{~mm}$ and $\mathrm{s} / \mathrm{C}=\mathbf{0 . 6 5 5}$}

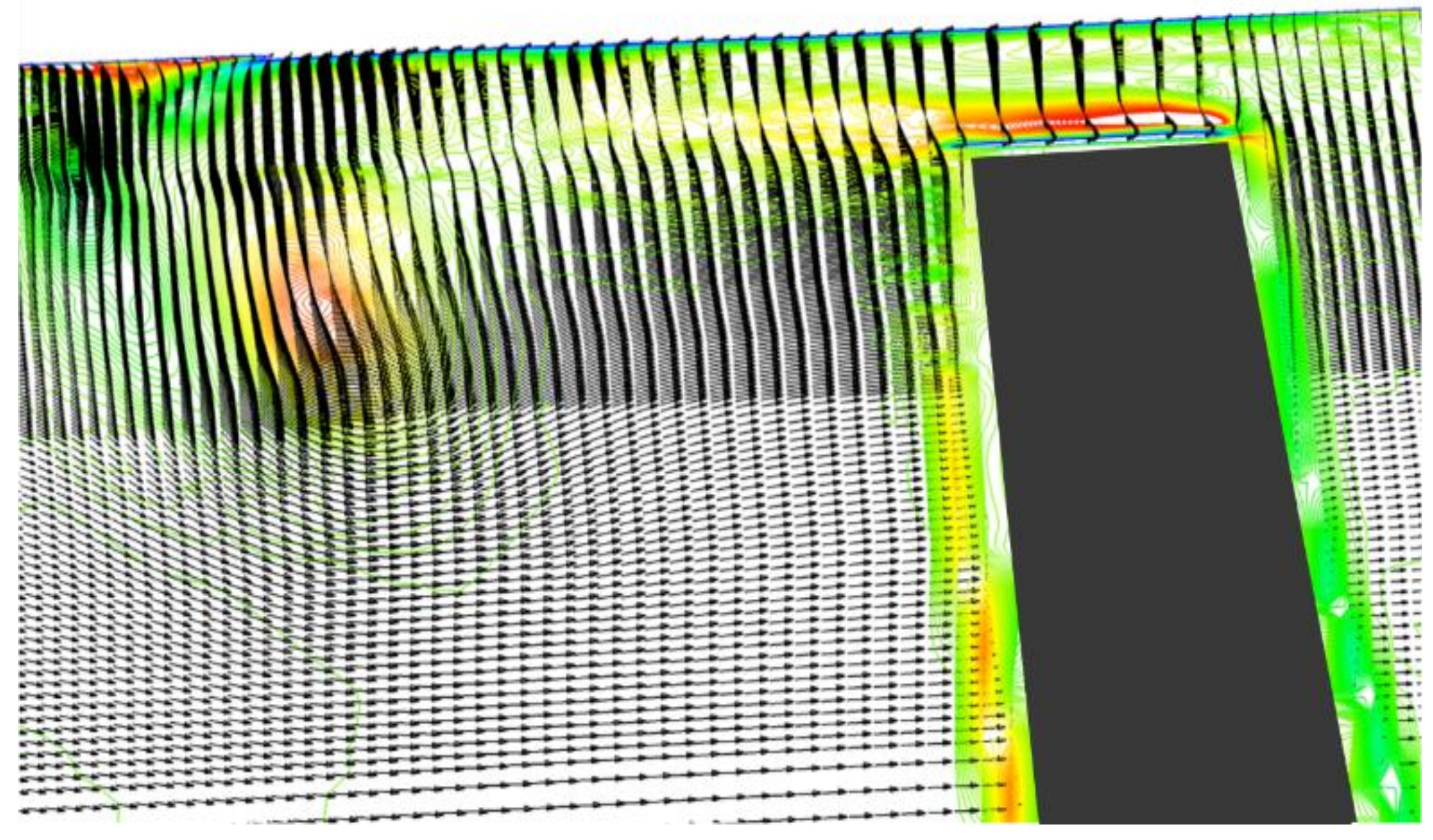




\section{Unsteady behavior of tip clearance vortex}

- Tip clearance vortex is transitional and never converges to the time-averaged structure.

- Flow control strategy should be based on the unsteady structure of the tip clearance flow. 


\section{Concluding remarks}

- Tip clearance flow is highly transitional at all flow conditions.

- Vortex ropes are observed at all operating conditions and play important roles in unsteady nature of tip vortex.

- Any flow control strategy should be based on the detailed unsteady tip flow structure. 